\title{
Logical framework of quality of care in family planning in China: client-centered approach
}

\author{
Zhenming Xie ${ }^{1}$
}

Received: 14 February 2018 / Accepted: 15 May 2018 / Published online: 30 July 2018

(C) Springer Nature Singapore Pte Ltd. 2018

\begin{abstract}
The year 2018 marks the 40th anniversary of China's reforms and opening to the world. As an important part of the overall reform effort, reform of the national family planning program, begun in the 1990s as a pilot project focused on quality of care, has achieved historic and significant results. The pilot project, conducted by the State Family Planning Commission of China in a few select areas, was a response to the 1994 International Conference on Population and Development in Cairo, as well as to a range of social and economic changes in China. To achieve quality of care, the pilot project adopted a client-centered approach to refocus China's family planning efforts on client needs and rights, informed choice of contraceptives and the provision of better quality services. After nearly 10 years of trials, the successful experiences of the pilot project served as the basis of a family planning program reform rolled out nationwide. This paper uses a logic framework approach to review the main activities, outputs, and impacts of the pilot project. The paper argues that the quality of care project not only developed a model that facilitated reorientation of China's earlier family planning efforts, but has also provided experiences and lessons that can serve as references for the implementation of "Healthy China 2030" in the future.
\end{abstract}

Keywords Quality of care project · Family planning $\cdot$ Reorientation of family planning program $\cdot$ Scale up

Zhenming Xie

zmxie@cpdrc.org.cn

1 China Population and Development Research Center, Beijing, China 


\section{Introduction}

In the early 1990s, as part of a general review of reforms supporting economic growth, social transformation, and the rise of a market economy, China's family planning program was examined with an eye to making improvements. In particular, there was general agreement that the family planning program should not be focused exclusively on meeting demographic targets, and that the reliance on administrative procedures to implement birth control policies was not ideal and that alternative approaches needed to be considered. At this time, participants at the 1994 International Conference on Population and Development (ICPD) reached a consensus concerning the meaning of "reproductive health" and established the principle that human beings themselves, rather than the aggregate numbers of human populations, should be at the core of all population and development activities (UNFPA 1996; Gu 1996).

As a response to both internal and external challenges, the State Family Planning Commission of China (SFPC) formally proposed new guidelines known as the Two Reorientations (liangge zhuanbian) in October 1995. First, the family planning program would no longer be focused solely on controlling the number of births, but would be integrated closely with measures for economic and social development in order to address population issues in a comprehensive manner. Second, the method for implementing the program would shift gradually from relying primarily on social constraints such as fines or administrative punishments to an interest-oriented approach, and a mechanism for integrating comprehensive services, scientific management, and family planning awareness education would be institutionalized (Peng 1996). Simply put, the two reorientations were intended to refocus China's family planning program from a concern with meeting demographic targets to one of meeting client needs. The two reorientations proposal marked the beginning of China's journey to reform its family planning program.

China's family planning program had achieved a certain amount of international recognition in the 1990s. Designed primarily to control the number of births, an austere family planning apparatus consisting of strict fertility policies, strict organizational networks and strict regulatory measures was in place. This apparatus was very effective in controlling population growth, but did so at a high cost. In early 1995, SFPC launched a pilot program called the Quality of Care in Family Planning project (the QoC project) in select counties and districts. The purpose of the pilot program was to introduce a client-centered approach to the family planning effort and explore ways to realize the two reorientations. The pilot program was a success, leading SFPC to expand the scope of the program and promote changes to the family planning effort on a national scale.

The year 2018 marks the 40th anniversary of China's reforms and opening to the world. Reform of the national family planning program, begun in the mid-1990s, has been an important part of the overall reform effort and has achieved historic and significant results. Established in 1981, for 32 years the State Family Planning Commission of China (renamed the National Population and Family Planning Commission of China in 2003) was an independent administrative entity reporting to 
the State Council, until 2013 when this agency was merged with the Ministry of Health to become the National Health and Family Planning Commission of China. In 2015, after being strictly enforced for more than 35 years, China's one-child policy was replace by a two-children policy. Today Chinese people enjoy more freedom to choose the number and spacing of their children, and China's family planning program is getting closer to realizing the goal set by the 1994 ICPD in Cairo. Reforms of China's family planning program have, after more than 30 years of effort, achieved a soft landing.

I participated in the QoC project and witnessed the entire process from start to finish. Based on my own experiences, in this paper I review the logical framework of the quality of care approach that was key to the pilot project, and summarize the experiences and lessons learned from the project. I conclude that the client-centered methods introduced by the QoC project represent best practices in the field of family planning and reproductive health. Moreover, because the needs for family planning services and reproductive health care are increasing, the QoC project's clientcentered approach can be useful as a reference to support implementation of the "Healthy China 2030 Planning Outline."

This review of QoC project from the mid-1990s to the early 2010s, including an introduction to major activities, outputs, and impacts of the project in China, is based on a case study that examines the logical framework of the QoC pilot project. Part of the quantitative data and qualitative information used in this paper comes from the documents for QoC projects I have worked on. I kept most of these records in my own notebook. The stories, events and recalls cited in the paper are selected by me from the QoC project memoir, submitted by more than 20 participants including senior management officials, researchers, and grassroots leaders, all of whom took part in the experiments carried out during the project. I am one of editors of the memoir and have permission to use the information for this paper.

\section{Concept behind the QoC project}

The QoC project began as a domestic social reform effort, but soon received international assistance. The Ford Foundation provided funding for a resource team of foreign and domestic experts who participated in the main activities of the project. The team introduced advanced international concepts and scientific methods to the project.

In 1996 the QoC project resource team introduced a Chinese translation of "Fundamental elements of the quality of care: a simple framework" (Bruce 1990), an article written by Judith Bruce of the Population Council. Her study summarizes the experiences of some 100 developing countries in providing family planning services and argues that quality of care in family planning services increases the satisfaction of level of couples of child-bearing age, raises the contraceptive use rate and leads to a decline in fertility. Bruce explains that quality of care in family planning consists of six elements: (1) clients are able to choose a contraception method; (2) information about contraception given to clients; (3) service providers with technical competence; (4) the development of interpersonal relations; (5) mechanisms 
for follow-up and continuity; and (6) availability of a constellation of appropriate services.

Of Bruce's six interrelated elements, allowing clients to choose the contraceptive method is the most important. Without improvements to information availability, family planning education and communication channels, it is difficult to provide clients with sufficient information about contraception. If service providers lack technical expertise, it is hard for clients to get the contraceptive methods they need. Supportive interpersonal relationships between service providers and clients facilitate better communication and increase client satisfaction. Finally, after the choice of contraceptive method, the availability of suitable follow-up services and related comprehensive services are directly related to contraceptive effectiveness.

However, before the QoC project began in 1995, it was difficult for some service delivery points (SDPs), especially in rural China where the limited family planning services focused mainly on birth control, to provide clients with the information needed to make informed choices of contraceptive. One-child policy implementation was based on parity prescriptions of reliable contraceptives: the intrauterine device (IUD) after the first birth and sterilization (male or female ligation) after the second birth. Women were obliged to accept an IUD or sterilization soon after childbirth, and those with IUDs were required to obtain regular ultrasound checkups to confirm that the device was in place and that they were not pregnant (Kaufman et al. 2006). In some SDPs, IUD users were required to deposit money as a safeguard against the birth of another child, and the deposit was returned only in the event of sterilization or infertility. County family planning commissions and the higher level agencies these commissions reported to used indicators related to contraceptive use to evaluate the effectiveness of family planning efforts. This resulted in very high IUD insertion and sterilization rates, and timely acceptance rates. The client's needs and health concerns were often ignored. No counseling was offered to assist clients in making a choice of methods, and minimal medical follow-up was provided.

In short, changing to a program that allowed clients to make informed choices about contraception would involve making considerable changes to program management and evaluation methods. Basing assessments of the long-term contraceptive use rate, and on the rates of sterilization and IUD use would no longer be appropriate. But many leaders worried that removing evaluations of long-term use rates could lead to a drop in contraceptive prevalence, a rise in the failure rate and fertility increases. The QoC project was an effort to explore ways to introduce an informed choice approach in a limited number of pilot counties and districts, and then use the experiences gained to expand successful approaches to more parts of China.

Dr. Baochang Gu a consultant for the operational office of the QOC project, introduced informed choice into the pilot project. He suggested that "a slight change in family planning service may affect the reform program as a whole, and introducing informed choice is like pulling one hair to affect the whole body." While informed choice seems, on the surface, like a straightforward service concept, its introduction actually affects the reform program as a whole, and requires changes in technology, management and regulations related to the family planning program ( $\mathrm{Gu}$ et al. 2002).

When visiting a village in Nongan county in 1997, Ruth Simmons, an international expert from University of Michigan, saw the Chinese version of Bruce's six 
elements of quality of care posted on the walls of local homes. People told her that the same walls had once been used to display Chairman Mao's portrait and quotations. Chinese farmers might not have fully understood these new concepts, but they knew quality of care was what they needed (Xie and Tang 2008).

One day during my time at the QoC project operational office, I received an anonymous letter from the United States. The letter criticized the way we had translated "quality of care" into Chinese. The writer pointed out that our translation of "youzhi fuwu" simply meant "quality service", while the word "care" in English suggested more than just "service", including also notions of affection and respect for clients. The letter suggested we change "youzhi fuwu" to "youzhi anhuai" meaning "quality care." I fully understood the intention of this letter. It reminded us not to limit our understanding of "quality of care" to include only a range of technical services, while forgetting the underlying purpose of initiating the QoC project in the first place. It was crucial that we did not lose sight of the objectives of the QoC project at any point during the implementation process.

\section{Purpose of the QoC project}

Besides of some specific objectives for pilot counties and districts, the overarching purpose of the QoC project was defined as a way to promote the macroscopic goal of realizing family planning reform. In late 1995, at the beginning of the Ninth FiveYear Plan (1996-2000) time period, the SFPC issued a formal call for reorientation of the family planning program. In early 1998, it elaborated on the goals of the reorientation effort, explaining that by the year 2000 innovative experiments in a number of pilot counties and districts were expected to yield results that would allow the client-centered, quality-focused family planning approach to be gradually expanded nationwide. It was hoped that the nationwide rollout of the reorientation of the program would be realized by the year 2010 (Xie 2011).

The SFPC began with a call for the reorientation of the family planning program, and then launched pilot program experiments to demonstrate how the program could be reoriented and what a client-centered, quality-focused family planning program might look like in the Chinese context. The pilot experiments also sought to convince leaders and others involved in China's family planning effort at all levels throughout the country of the feasibility of the reorientation process. This building of consensus was seen as integral to preparations for the full-fledged, nationwide promotion of the reorientation of the family planning program after 2000 .

Three specific objectives drove the pilot experimentation process forward: changing the thinking of people working for family planning agencies, upgrading family planning management and services, and improving family planning facilities and institutional support (Gu et al. 1999). 


\subsection{Changing people's thinking}

China's family planning program was focused on controlling the number of births for a long period of time. This approach was the only one program managers and service providers had ever experienced and they found it very difficult to conceptualize, implement or manage the family planning program in a new, alternative manner. Some worried that negative demographic consequences would result from a less rigorous approach to birth control. Some local managers and service providers resisted the pilot programs because they were required to take on greater workloads and accept more responsibility. Others worried that the new approach would be unappreciated by clients, many of whom were poorly informed and unaware of their reproductive health needs and rights, or even skeptical that they had such needs and rights. Thus, changing the thinking of people working in the family planning system and getting them to accept a client-centered approach was a priority of pilot project experiments.

\subsection{Upgrading management and services}

Once the client-centered approach was in place, the quality of services and the care of clients tended to become priorities for the program. But managers and service providers often discovered that they did not have the capacity to provide services that achieved the goals and satisfied the requirements of the experiments. For example, while providers were trained to insert and remove IUDs, they had not been trained to explain the advantages and disadvantages of the various types of IUDs available, nor were they knowledgeable about the potential side effects of a given IUD. The providers lacked the expertise needed to provide pre-operation counseling and post-operation follow-up services and received no professional training in interpersonal communications. For these reasons, the upgrading of management and services was a key component of the pilot QoC project.

\subsection{Improving facilities and institutional support}

When the quality of services rather than meeting demographic targets became the focus of family planning efforts, many aspects of the program, including facilities, resource allocation, contraceptive supply and staff recruitment, had to be restructured. Greater priority had to be given to maintaining aseptic conditions in clinics and to service procedures and protocols. More space had to be allocated for examinations and counselling, and more attention paid to the privacy and confidentiality requirements of clients. Many local service clinics in the pilot areas were expanded or renovated, and the equipment needed to provide quality family planning and reproductive health services was installed. With support from local governments, additional resources were allocated and more qualified, capable staff were recruited. It was clear that improving facilities and increasing the level of institutional support were necessary to safeguard the success of the pilot experiments. 


\section{Assessment and evaluation}

As new concepts developed outside of China were introduced, some issues concerning implementation, supervision and assessment needed to be addressed in the pilot project counties and districts. Therefore, scientific methodologies, such as the logical framework approach, situation analysis and in-depth assessment were adopted by the resource team for the QoC project.

The logical framework approach (LFA) was originally developed by USAID in 1970 and was introduced to China in late 1990s as a tool to support design, planning and evaluation of various kinds of projects (Zhang 1998). The QoC project adopted LFA in 2001, using it to examine the management and evaluations systems of the QoC project as part of the effort to reform the traditional approaches to family planning management and evaluation. This paper has also made use of LFA to provide a scheme for summarizing and analyzing the results of implementing the QoC project.

Dr. Jay Satia from the International Council on Management of Population Programmes (ICOMP) and Mr. Erli Zhang from SFPC Planning and Statistics Department, with support from consultants involved in the management and evaluation reform effort, developed a logical framework matrix for the QoC pilot project. Project aims and causality were divided into five-layer categories: the project objectives, the impacts (outcomes), outputs, activities and inputs. The aims of each level were divided into four columns: aims of the project, objectively verifiable indicators, means of verification, and risks or assumptions. It is a $5 \times 4$ matrix in this case. In accordance with the result-oriented vertical logic relationship of the logical framework approach, this paper presents objectively verifiable indicators for macro goal and specific objectives, impacts, outputs, and main activities of the pilot project (see Table 1).

After the pilot QoC project began, research efforts in the project counties and districts received national and international technical assistance to identify essential activities, outputs and outcomes to support expansion of the project to other regions of China. Randomly selected program managers, service providers, and married women of reproductive age in project counties/districts completed a baseline questionnaire survey in 1995 and a follow up questionnaire survey in 1998. Also in 1998, a team of 20 Chinese researchers, project staff, and two international experts conducted an in-depth qualitative assessment in six project counties/districts to obtain additional data. The qualitative assessment provided an opportunity for key Chinese professionals involved in the quality of care movement to review the results of applying quality of care principles in practice, and allowed Chinese and international experts to share and compare global and Chinese experiences with quality of care.

Compared with the baseline survey results, results of the follow-up survey and qualitative assessment in 1998 showed many positive changes: women enjoyed more freedom in choosing a contraceptive method; relations between clients and providers had improved; positive feedback from local people showed 
Table 1 Logical framework of the quality of care pilot project

\begin{tabular}{|c|c|}
\hline Aims of the project & Objectively verifiable indicators \\
\hline Macro goal & $\begin{array}{l}\text { Promoting reorientation of China's family planning program from a focus on } \\
\text { meeting demographic targets to meeting client needs }\end{array}$ \\
\hline Specific objectives & $\begin{array}{l}\text { Change the ideology } \\
\text { Upgrade management and services } \\
\text { Improve facilities and institutional support }\end{array}$ \\
\hline Impacts/outcomes & $\begin{array}{l}\text { Impacts on clients } \\
\text { Reduce contraceptive failures } \\
\text { Fewer abortions due to unintended pregnancy } \\
\text { Impacts on program } \\
\text { Stabilize fertility at a low rate } \\
\text { Improve the image of the family planning program }\end{array}$ \\
\hline Outputs & $\begin{array}{l}\text { Informed choice of contraception method } \\
\text { Content and style of information, education, and communication (IEC) redefined } \\
\text { Clinical services standardized } \\
\text { Life-course services provided } \\
\text { Certain administrative restrictions lifted }\end{array}$ \\
\hline Activities & $\begin{array}{l}\text { Informed choice of contraception method } \\
\text { Information, education, and communication (IEC) activities } \\
\text { Clinical services } \\
\text { Rights protection } \\
\text { Interpersonal relationship building } \\
\text { Changes to administrative measures }\end{array}$ \\
\hline Inputs & $\begin{array}{l}\text { Leader's responsibilities } \\
\text { Financial inputs } \\
\text { Personnel, facility and equipment inputs } \\
\text { Legal administration }\end{array}$ \\
\hline
\end{tabular}

that clients welcomed quality of care approaches, as did the service providers and managers working at the grassroots level. Because fertility remained stable at a low rate, local leaders put aside their earlier anxieties and became supportive in implementing the refocused family planning program. The research results were compiled as "A General Assessment Report on Quality of Care in First Batch of National Family Planning Commission's Pilot County and District" and published as a collection in 1999 (Zhang et al. 1999).

\section{Results and changes observed}

Changes in the mix of contraceptive methods used by women was mainly the result of promotion of informed choice. At the same time, the approach to educating the public about family planning was improved, and people living in the project areas received 
more information about family planning and reproductive health. In addition, both services and facilities were upgraded, resulting in clients receiving better quality clinical services, counseling and follow-up services. Finally, all of these improvements were supported by changes in family planning administrative and management practices.

\subsection{Informed choice and changes in the contraception mix}

Informed choice is the key component of client-centered service. For many years, IUDs had been recommended by providers of family-planning services for spacing of births, and sterilization for limiting the number of children born. As informed choice was integrated into China's reoriented client-centered family planning effort, more clients received counseling before choosing a contraceptive method, more diverse contraceptive methods were made available, and more clients made their own decisions.

In addition, the mix of contraceptive methods became more diversified and was no longer dominated by IUDs and sterilization, implying that individual clients had more input in the selection process. Ms. Huimin Shao, former director of the family planning commission of Deqing county in Zhejiang province, recalled that "the assessment in 1998 found that after the introduction of informed choice, there were no complications to birth control operations in Deqing, and the contraceptive prevalence rate was more than $92 \%$. The mix of contraceptive methods in use had changed significantly. Among 14,339 users, 44.8\% used IUDs, 12.2\% sterilization, $31.2 \%$ used condoms, $10.5 \%$ took birth control pills or injections, and $1.3 \%$ chose other methods. The percentages of sterilization or IUD had both declined, and the percentage of condom use had obviously increased. The method mix was more reasonable than in the past."

Changes to the method mix are a positive indication that there had been a transition from government dictating method choice based on parity to individual couples making their own choices. Before the QoC pilot project began, 38.7\% of survey respondents reported that the contraceptive method they used had been required or recommended by family planning workers. After the QoC project got underway, that percentage dropped to $17.8 \%$. More women consulted with service providers or had discussions with their husbands before they choose a method. Furthermore, women's knowledge of the contraceptives that they chose to use improved markedly; for example, women became more familiar with the types of IUD available, their functions and possible side effects of various types. Reports from pilot project locations also indicated that abortion rates decreased as contraceptive choice and follow-up increased. This finding was attributed to a decrease in contraceptive failures (Gu 2000; Population Council 2000).

\subsection{Improved approaches to educating the public}

Considerable funding and human capital were devoted to reforming the approach to education about family planning. Major changes were made to readjust the focus of 
awareness education and to make sure that people in the project areas had sufficient information about family planning.

Before the QoC pilot project began, education consisted of family planning workers distributing materials listing family planning regulations and policies to families. Because the materials were often difficult to read and uninteresting, they were not of interest to ordinary people. The QoC project introduced educational materials that focused on issues related to family planning and family health. Visually engaging presentations using text, pictures, and graphics provided people with information about a wide range of topics, including contraceptive choices, breast feeding and the nursing of infants, how to prevent reproductive tract infections and an introduction to health needs at different life stages. Radio, television and public bulletin boards were used to promote educational materials and increase the reach of the family planning education effort.

Mr. Deguang Chen, former director of the family planning commission of Nongan county, Jilin province, recalled how his agency worked to improve family planning awareness education. He said, "Before the QoC pilot project, we distributed propaganda leaflets to the masses that had no illustrations and were about birth policy and regulations. The masses were not interested in this, and they put the leaflets aside without giving them a thought. Children folded some of the leaflets into paper planes, and adults sometimes used them to roll cigarettes. Later, the village leaders said that their superiors would check on what happened to the leaflets, so villagers pasted them high on beams where the children could not reach them and the adults could not see them clearly." Mr. Chen then talked about what happened after the QoC project began. "We improved the educational materials, making beautiful fullcolor leaflets that provided information about reproductive health and contraceptive methods. In order to aid family planning workers doing house to house promotions, we designed a wooden box and put the educational materials and contraceptives inside. People could look and touch the materials. Later we substituted a handbag for the wooden box, making the process more convenient. Family planning workers brought the hand-bag with them when they visited family households for consultations. People could examine an IUD while learning about contraception principles and use procedure, and related family planning matters."

The change in approach to family planning education greatly empowered all of the people involved. Clients became more knowledgeable and aware and more likely to participate in family planning activities, helping service providers, managers and leaders to improve the effectiveness and quality of family planning and reproductive health care services.

\subsection{Improved quality of services}

With the reconstruction or renovation of service sites in pilot counties, townships and villages, a client-friendly environment was created. Waiting areas had information and educational materials available and a video display, while touch-screen information counseling systems were set up in reception areas. 
Table 2 Percentage of women receiving counseling and follow-up services before and after 1995, as reported by women at pilot sites. (Source: Zhang et al. 1999)

\begin{tabular}{llll}
\hline Service provided before or after the procedure & Family planning procedure & Service received (\%) \\
\cline { 3 - 4 } & & Before 1995 & After 1995 \\
\hline Introducing advantages and disadvantages of & Female sterilization & 61.1 & 93.7 \\
contraceptives & IUD insertion & 66.6 & 89.9 \\
Explaining the family planning procedure & Female sterilization & 50.5 & 81.0 \\
& IUD insertion & 56.9 & 85.2 \\
Explaining possible risks and how they can be & Abortion & 50.5 & 70.5 \\
dealt with & Female sterilization & 79.8 & 93.7 \\
& IUD insertion & 81.0 & 94.9 \\
Making a follow-up appointment & Abortion & 67.9 & 86.0 \\
& Female sterilization & 65.0 & 77.8 \\
& IUD insertion & 71.2 & 91.8 \\
\hline
\end{tabular}

Standard operating procedures (SOP) for family planning services emphasized the provision of quality of services, especially counseling before choosing methods, and follow-up services after procedures (see Table 2), neither of which had received adequate attention in the past. Clients had more varieties of contraceptive methods to choose from, giving people more options to choose the most appropriate method for spacing or limiting births.

\subsection{Expanded scope of services}

Once the QoC pilot project was underway, pilot sites greatly expanded the range of family planning services available and began to offer related reproductive health care services, such as the diagnosis and treatment of reproductive tract infections. Many pilot sites launched reproductive health care life cycle services for people in different age and sex groups. Such services included, for instance, sex education and contraception information for adolescents and health care services for women in menopause. Check-ups for the treatment and prevention of gynecological diseases were considered core components of the "universal access to primary reproductive health care" campaign at pilot sites. The 1998 follow-up survey found that about $90 \%$ of women living in pilot areas had had a gynecological check-up, a much higher proportion than the national average (from 61 to $65 \%$ ).

\subsection{Changed administrative and management practices}

Reorienting management thinking and changing administrative and management practices were considered key aspects of the QoC project by people working at all levels of the project. After years of efforts, thinking did change and this brought with it changes to administrative and management practices. For example, the "Birth 
Permission Certificate" was changed to the "Reproductive Health Service Record Handbook" (this change would eventually be implemented nationwide). The handbook recorded information about the types of contraceptive used and any changes, and dates of pregnancies, maternity check-ups and childbirths, as well as other service records.

A computerized information system was set up at pilot sites to keep records of childbirths and contraceptive use. Data in the system was used by management to compile statistics and by service providers to keep track of when clients required services or follow up visits.

Pilot sites explored new ways of evaluating their performance. They experimented by modifying evaluation indicators, adding new indicators, or changing evaluation methods. Many sites added information on client satisfaction to the content of their evaluations. The duration of the pilot project may have been too limited to test the effectiveness of new indicators or evaluation methods. However, the effort to improve evaluation effectiveness during the QoC pilot project is serving as the basis of continuing efforts to reform evaluation methods.

\section{Impacts and implications}

The outcomes of the QoC project were analyzed from the perspective of the clients and from that of the service system. Some outcomes had direct and immediate impact while others are having a long-term impact.

\subsection{From the client's perspective}

The feedback from local people about the pilot project was very positive and supportive. People appreciated the improved services, and especially liked the more personalized communications that took place while the services were being provided. More people felt respected and cared for by service providers. The providers spent more time listening to clients in order provide suitable contraceptives as well as to meet the reproductive health needs of clients. Managers were concerned with how people reacted to the quality of care approach and whether they were satisfied with the services. The attitudes and behavior of family planning personnel made it clear to clients that they were no longer simply patients to be looked after, but were active participants in the family planning process, individuals who were respected and cared for.

Counseling sessions, adoption of an informed choice approach, knowledgefocused awareness education, and follow-up visits were all key components of QoC project experiments, and these helped clients, particularly women, become more knowledgeable about contraceptive use. The women who benefited from the project were, in turn, motivated to participate more actively in informed choice. Including the user in the family planning process and making them responsible for family planning decisions resulted in fewer unnecessary contraceptive failures and fewer abortions. According to the statistics from a single pilot county, the cases of unintended 
pregnancy in the first 9 months of 1998 were 57\% fewer than those from the same period in 1995.

\subsection{Impact on the service system}

Service facilities were greatly improved and more qualified personnel were recruited to meet the service provision requirements of the quality of care approach in the pilot areas. There were notable changes in the age structure and service knowledge of the local service providers. In addition to hiring more qualified staff, enhanced training strengthened the technical expertise of service providers at family planning facilities. For example, during the 3 years of the pilot project, the number of technicians increased from 7 to 12 in the county-level service stations in Deqing county, while Yandu county recruited 60 university or polytechnic school graduates to join the family planning service team. Intensive on-the-job training was offered to help staff get up to speed with standardized service procedures, learn new technology, improve technical skills and become more effective interpersonal communicators.

All of the pilot locations allocated resources to improve the service environment at county, township and village levels to ensure that each service station had standardized service rooms for different functions. Guidelines that standardized the delivery of technical services and made counseling an integral part of the entire family planning process from beginning to follow-up visits were formulated and implemented.

\section{Expansion and scaling up}

Based on the outcomes discussed above, some suggestions and policy ideas were included in the assessment report of 1998 and later initiated: (1) a study of management and evaluation systems for the QoC project, headed up by Mr. Tiemin Wang, former vice-director of family planning commission of Tianjin; (2) improved counseling for informed choice with Dr. Junqing Wu, professor at the Family Planning Institute of Science and Technology of Shanghai, as team leader; (3) a testing and referral program for the treatment of reproductive tract infections (RTIs) with Mr. Lifang Yang, former vice-director of family planning commission of Jiangsu, as team leader. Meanwhile, the expansion of the quality of care project to less developed western parts of the country with Dr. Kaining Zhang, professor of University of Yunnan, as team leader, and later a study on gender perspective headed up by Bohong Liu, professor of the Women's Institute of National Women's Federation of China were also introduced as new subprojects.

The successful experiences of the QoC project were transferred to other projects and areas, such as United Nations Population Fund (UNFPA) projects, the China-Japan Integration Project, the SFPC's project on "Changing the Approach to Information and Education," an effort to bring a new conception of marriage and childbearing to thousands of households (hun yu xinfeng jin wanjia). Provincial and prefecture level governments also made use of ideas from the QoC project in their 
own quality of care family planning efforts. The number of counties or districts that made use of some of the experiences of the QoC project increased steadily from around 200 in 1998 to about 300 in 1999 and as many as 827 by the end of 2000, according the records of the SFPC general administration office.

SFPC used a careful summary of the QoC pilot project as the basis to promote the quality of care in family planning to the country as a whole. In July 2000, the SFPC issued a document entitled "Opinions on the Overall Promotion of Quality of Care in Family Planning," which marked the beginning of a comprehensive, topdown development stage for the QoC project.

By June 2002, the SFPC has decided to move forward with the "Action to Establish National Advanced County-level Units for Quality of Care in Family Planning" ("Advanced Units for QoC"), and required that the scope of the QoC project gradually be expanded to the whole country. The SFPC leadership group for the QoC project asked the project's operational office to develop a new assessment system for the action, including assessment criteria to determine whether candidate counties or districts should be accepted as national Advanced Units and evaluation indicators for the national Advanced Units for QoC. The operational office used the logical framework approach to develop a proposal for evaluation indicators as criteria to choose advanced counties, and a working plan to assess whether candidate counties or district should be accepted. After collecting opinions and making revisions, the proposal was formally submitted to the SFPC leadership.

In February 2003, the National Population and Family Planning Commission (NPFPC, the SFPC was renamed the NPFPC in early 2003) issued a document with an evaluation index system for national Advanced Units for QoC, and a set of objectively verifiable indicators to measure the activities, outputs and impacts of the applicants for advanced county status that had been recommended by the provinces. The new evaluation system stipulated what the content, direction and goals of the establishment action should be at all levels, and provided means and strategies to assess whether candidate areas should be accepted as Advanced Units.

Beginning in the year 2003, the action to establish Advanced Units for QoC was pushed vigorously nationwide. Each year, the NPFPC organized "acceptance teams" composed of government officials, scholars and experts to conduct on-site evaluations and determine whether a new area should be accepted as an Advance Unit for QoC. The acceptance activities lasted for a full decade and I am proud to say that I participated in these activities every year during this decade. By the end of 2013, a total of 1818 counties, districts and cities had been assessed and accepted as national Advanced Units for QoC, accounting for about $63 \%$ of the 2853 county-level units in total. Provinces and cities also assessed more advanced units at the provincial level. The quality of care approach to family planning and reproductive health services basically achieved full coverage throughout China. 


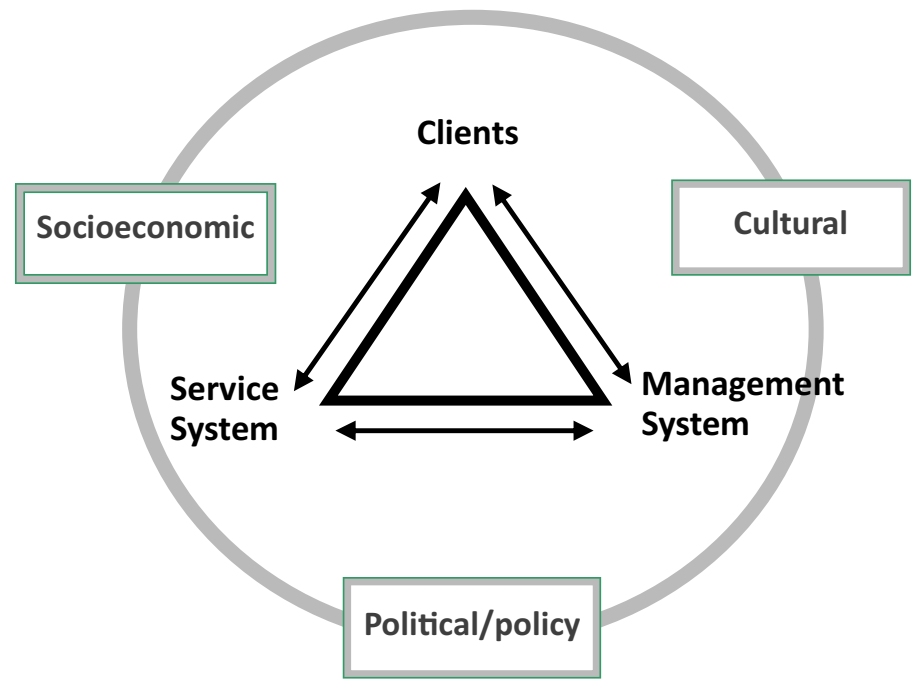

Fig. 1 Three-element framework of the QoC project

\section{Experiences and lessons learned from the pilot project}

The successful QoC pilot project not only developed a model for program reform, but also provided people who followed the project experiments with valuable experiences and lessons.

In 2005, with assistance from Prof. Ruth Simmons and Dr. Jay Satia, the QoC project operational office organized a group of Chinese experts and scholar to write and publish Guide Book on Quality of Care in Family Planning (Xie et al. 2007). The chapters in this guide book present the practical experiences and lessons that grew out of the $\mathrm{QoC}$ project. This paper reviewed the conceptual framework of the quality of care approach, and has also presented some experiences and lessons which might be of use to people currently involved in family planning work.

\subsection{Client-centered interaction among three elements in the QoC project}

In June 2000, SFPC Director Weiqing Zhang used a "three-element framework" chart $^{1}$ in his speech at the National Seminar of On-site Experience Exchange of Family Planning and Reproductive Health, held in Qiqihar, Heilongjiang province, to illustrate the conceptual framework of the quality of care approach. He said,

\footnotetext{
${ }^{1}$ The "three-element framework" chart was first introduced to China in 2000 by a team from the World Health Organization headed by Ruth Simmons and Peter Fajans in order to study the "Strategy for Strengthening Reproductive Health Policy and Programs" in Chongqing, China. Director Zhang Weiqing adapted it for the OoC Project; it represents an adaptation of the WHO Strategic Framework, which was published in 2007 as The WHO Strategic Approach to Strengthening Sexual and Reproductive Health Policies and Programmes (World Health Organization 2007).
} 
"Practices from all over the country demonstrate that quality of care in family planning is the dialectical unity and optimal combination of clients, service system and management system (Zhang 2000)."

The "three-element framework" provides a tool for observing and analyzing the QoC project. The three elements triangle illustrates the combination into an organic whole of clients, service system and management system (Fig. 1).

"Clients" are at the top of the triangle, meaning that the needs and rights of clients should always be the top priority of the QoC project. "Service system" shown at the lower left of the triangle is responsible for delivering medical care appropriate to family planning and reproductive health needs, and for overseeing the use of technology, providing information and offering counseling services."Management system" at the lower right of the triangle includes planning, operational management, and evaluation; it provides the institutional guarantee for the QoC project.

In the three-element framework for the client-centered QoC project, all three elements—client, service system and management system-must be present, interconnected and mutually supportive, functioning as an organic whole to meet client needs and protect client rights. The upgrading of the service system has resulted in clients receiving higher quality services. After the reform of the management system that removed information on sterilization quota fulfillment from evaluations of service providers, clients were free to choose the contraceptive methods and services they preferred. The participation of clients has been the dynamic force driving changes to the service and management systems to meet client needs.

Before the QoC project began, the clients of family planning service facilities were mainly married women of childbearing age. As the QoC project developed, and husbands and other family members became involved. The range of people considered clients expanded to include both married and unmarried women and men, and even adolescents and menopausal women. Faced with more, increasingly diverse demands from different groups of clients, family planning service agencies in some regions were overwhelmed and unable to meet the demand. This was especially the case in urban areas where there were few or sometimes no family planning service stations.

Xuanwu district of Beijing, ${ }^{2}$ an area in the center of the city with a population of 0.5 million population, was home to a large number of medical resources, including 14 hospitals and 28 community-health service stations, but not a single family planning technical service agency. After implementing the QoC project, Madam Xinhua Guo, former director of the family planning commission of Xuanwu, recalled how she used the medical resources of the health department to bring quality services to the community. She said in her memoir, "I proposed the idea of 'borrowing a stage for presenting a drama,' by which I meant borrowing medical resources from the district's health sector to provide family planning and reproductive health services. I reported this idea to the district leader, and got support. I repeatedly visited health bureau leaders to develop a joint solution." Under the leadership of district

\footnotetext{
2 In 2010, China's State Council approved the merger of Xuanwu district with Xicheng district, forming a new and larger Xicheng district in central Beijing.
} 
government and facilitated by public health resources, Xuanwu district started to deliver quality family planning and reproductive health services at the community level.

In 2013, China's State Council decided to merge the NPFPC and the Ministry of Health. There was agreement that integrating the resources of the two bodies would allow for improved delivery of family planning and reproductive health services as the part of public health services.

\subsection{Supportive external environment for the QoC project}

As Fig. 1 shows, the three elements triangle exists within a broader context consisting of the society, the economy, political life, and culture (Fig. 1). The SFPC decided to begin the QoC pilot project in the more economically developed eastern part of China, because it was felt that the favorable external environment would help the project get off to a good start. The success of the pilot project is evidence that this design decision was correct.

The subproject undertaken by Prof. Kaining Zhang's team to expand the QoC project expansion into central and western China during the years 2001-2003 was another success story. It proved that the QoC project could also be implemented in less developed areas. Professor Zhang recalled his experiences, and said that as long as the needs of the local people were satisfied, the project was understood and supported by the masses. In less developed areas, it is important to recognize that sometimes projects need to lower development thresholds and begin with limited targets that are achievable. At the same time, certain factors in less developed ethnic minority areas gave these areas their own uniquely favorable external environment. These factors, including multivariate minority cultures, somewhat more relaxed birth control policy, and good relationships between providers and clients, were supportive of the QoC project's effort to introduce new concepts and advanced methods in family planning and reproductive health.

Among external environment factors, political and policy support is the most decisive factor, and this support must be developed and maintained with governments at all levels. An important part of the work of the QoC project was advocacy directed at government leaders and decision-makers to obtain their commitments of support for the project.

\subsection{Government commitment to quality of care approaches}

The commitment of governments at four levels-state, province, prefecture and county-was key to the success of the QoC pilot project. The SFPC (the NPFPC after 2003), a central government entity, was tasked with family planning program reform and provided national-level leadership for the QoC project. The SFPC designed initiatives and oversaw implementation of the QoC project, and was in charge of expanding the successful pilot projects nationwide. Its tasks were to: 


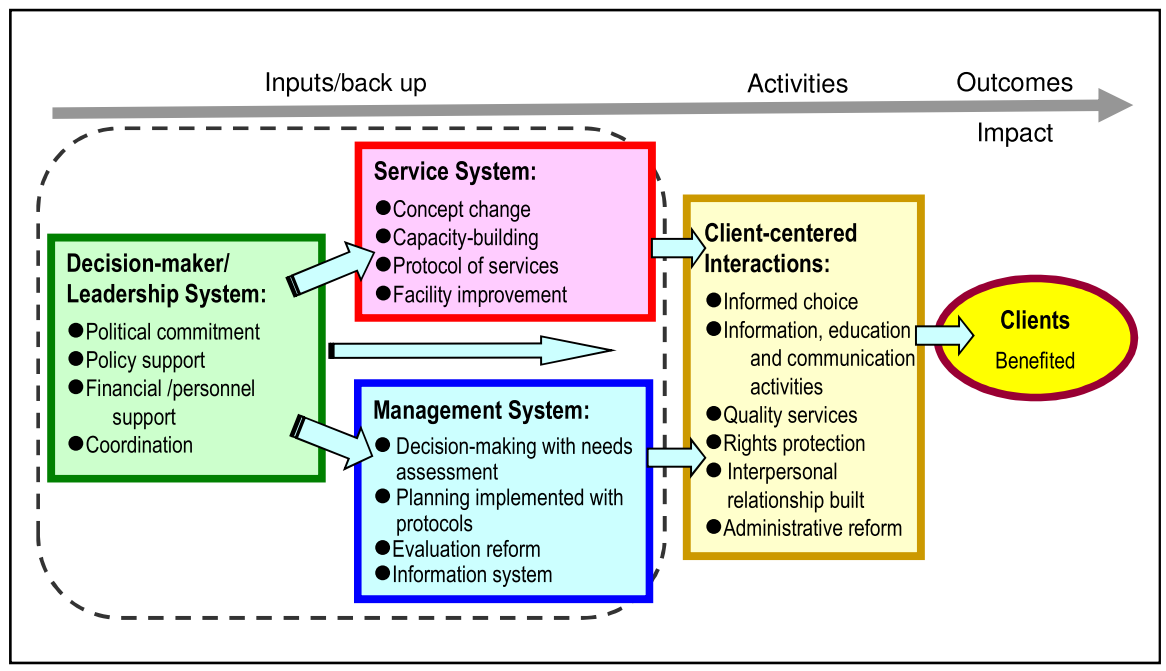

Fig. 2 Working mechanism of the quality-of-care approach in China

- develop national strategies, implementation plans and assessments of QoC project innovations, and lead the roll out of the project to whole country;

- coordinate relevant government departments to ensure policy support for the QoC project; and coordinate the efforts of universities, research institutions and non-government organizations to provide technical support; and

- mobilize financial and technical resources from international and domestic sources for implementing and scaling up the QoC project.

The leadership of provinces and prefectures in which pilot sites for the QoC project were located acted as liaisons between the state level and county or district level where the pilot experiments took place. The county or urban district is the basic administrative unit in China. Governments and family planning commissions at the county and district level made their own decisions about participating in the QoC project. They were encouraged to mobilize local resources to implement program reforms and innovations. In fact government leaders and decision-makers at all levels had input and helped to guarantee that the working mechanism of the QoC project functioned properly, and provided support for the reforms of service and management systems to implement client-centered interactions and meet client needs (see Fig. 2).

There were, nonetheless, some obstacles to implementing the project experiments, and especially some political risk. For example, I recall one pilot project county (that is best not named) carried out particularly bold pilot experiments. One year after the county had implemented an informed choice program for contraceptives as part of the QoC pilot project, the county's family planning commission refunded CNY 9.6 million to people who had paid deposits in lieu of sterilization after the birth of one child. This decision to issue refunds was supported by the county government. However, government leaders at the level 
above the county were still using traditional evaluation indicators to measure family planning performance. Because a couple of indicators did not satisfy the expectations of higher level officials, the director of the county's family planning commission was dismissed. Mr. Qingcai Feng, a retired QoC project expert and former vice-director of the family planning commission of Qingdao, recalls "that the obstacles to the QoC project came mainly from within the family planning system. There were two kinds of internal obstructions. Some people worried that population growth would spin out of control during implementation of the QoC innovations, and so they did not actively support the pilot work. We called this the inaction obstruction. Second was the bureaucratic obstruction, officials with autocratic work styles, who were jealous and ambitious, and would not tolerate different opinions." To succeed in introducing innovations, the QoC project had to oppose bureaucracy and overcome inaction.

\section{Conclusion and discussion}

The results of the QoC project demonstrate that quality of care in family planning in China is "an effective vehicle to bring change to family planning, and to family planning working methods and administrative procedures in accordance with the law". 3 Since the QoC pilot project started in 1995, delegations from many international organizations, both governmental and non-governmental, have visited China and toured the pilot areas. They were pleased to see the changes in China's family planning approach. The QoC project not only improved the service network, upgraded service capacity, and reformed management procedures, it also promoted the continuous modification and improvement of China's fertility policy.

A requirement of a birth-interval of more than 3 years, for example, had been required in China since 1978. The QoC project experimented with removing the requirement for a birth-interval in the pilot counties, and beginning in 2002 the requirement began being eliminated elsewhere in China. By 2013, almost every province had eliminated the birth-interval requirement, allowing the free spacing of births. The reform of fertility policy also proceeded step by step. China's strict onechild policy was introduced in the 1980s. The QoC project did not experiment with fertility policy adjustments, but the successful changes to service and management procedures introduced by the QoC project motivated people to study fertility policy adjustment. In 2013, the State Council broadened the exception for couples, allowing couples only one of whom was a single child to have two children. In 2015, the one-child policy was replaced by a universal two-child policy that was fully implemented in 2016. This gradual step by step reform process has made a qualitative leap in China's family planning program reform.

After a period of organizational restructuring and adjustments to fertility policy, leaders on the one hand and the public on the other hand have ended up with

\footnotetext{
3 The speech on 2002 Commendation Conference of National Advanced County-level Units for Quality of Care in Family Planning was delivered by Mr. Weiqing Zhang, Director of the SFPC, at a national video and telephone conference on July 14, 2002.
} 
different understandings of family planning work. At either end of the continuum of opinion, there are two extremes: some people believe that specialized family planning work should be eliminated and that these services should become a part of routine medical work; others believe that family planning work should continue unswervingly. In fact, the increasing needs for family planning and reproductive health services create new challenges. Institutional and policy reforms need to move forward without delay, and integrate resources so as to take advantage of medical technology from the health system and the family planning management network to meet the diverse demands of public health and to better serve the people.

In May 2016, the National Health and Family Planning Commission decided to carry out the "a new round of action to establish national advanced units for quality of care in family planning". This represents a further deepening and development of the QoC project under a new situation. It also sees quality of care in family planning as a starting point for reform and innovation, not the end point. I witnessed and participated in the entire QoC project. This paper is my effort to tell the story of family planning reform in China during past two decades. I hope the information here will support new rounds of reforms for quality of care in public health in the future.

\section{References}

Bruce, J. (1990). Fundamental elements of the quality of care: A simple framework. Studies in Family Planning, 21(2), 61-91.

$\mathrm{Gu}, \mathrm{B}$. (1996). Reproductive health and family planning: International perspectives and approaches (in Chinese). Beijing: China Population Press.

Gu, B. (2000). Reorienting China's family planning program: An experiment in quality of care since 1995. Paper presented at the Annual Meeting of the Population Association of America, Los Angeles, 23-25 March.

Gu, B., Zhang, E., \& Xie, Z. (1999). Toward a quality of care approach: Reorientation of the family planning program in China. In J. Satia, P. Matthews, \& A. T. Lim (Eds.), Innovation (Vol. 7-8). Kuala Lumpur, Malaysia: International Council on Management of Population Programmes.

Gu, B., Simmons, R., \& Szatkowski, D. (2002). Offering a choice of contraceptives in Deqing County, China: Changing practice in the family planning program since,1995. In N. Haberland \& D. Measham (Eds.), Responding to Cairo: Case studies of changing practice in reproductive health and family planning (pp. 58-73). New York: Population Council.

Kaufman, J., Zhang, E., \& Xie, Z. (2006). Quality of care in China: From pilot project to national program. Studies in Family Planning, 37(1), 17-28. This paper is also included in: Simmons, R., Fajans, P., \& Ghiron, L. (2007). Scaling up health service delivery: From pilot innovations to policies and programmes, WHO/ExpandNet, pp. 53-70.

Peng, P. (1996). Paper presented at the national symposium on exchanges of experiences of the "three integrations" in family planning (in Chinese), China Family Planning Yearbook 1996. Beijing: State Family Planning Commission of China.

Population Council (Ed.) (2000). Report on the international symposium on quality of care in China, November 17-19, 1999, Beijing. New York: Population Council.

United Nations Population Fund (UNFPA). (1996). Program of action adopted at the international conference on population and development, Cairo 5-13 September, 1994. New York: UNFPA.

World Health Organization. (2007). The WHO Strategic approach to strengthening sexual and reproductive health policies and programmes. Switzerland: WHO Press.

Xie, Z. (2011). Focusing on quality of care in the family planning program. In The Partners in Population and Development (PPD) (Ed.), Sharing innovative experiences, volume 19: Experiences in addressing population and reproductive health challenges. Global South-South Development Academy. http:// 
www.partners-popdev.org/wp-content/uploads/2014/12/Sharing-Innovative-Experiences-Volume-192011.pdf. Accessed 14 Feb 2018.

Xie, Z., \& Tang, M. (2008). From population control to reproductive health: Evolution of China's family planning program. In K. Zhang (Ed.), Reorienting concepts and methodology: 30 years of SRH [sexual and reproductive health] in China (pp. 1978-2008). Beijing: Social Sciences Academic Press.

Xie, Z., Wang, T., \& Feng, Q. (2007). Guide book on quality of care in family planning (in Chinese). Beijing: China Population Press.

Zhang, S. (1998). Post-project evaluation: a series of teaching materials on project management (in Chinese). Beijing: Tsinghua University Press.

Zhang, W. (2000). China's population and family planning program in the 21 st century. Paper presented at the international conference on quality of care, Beijing, 6 June.

Zhang, E., Gu, B., \& Xie Z. (Eds.). (1999). Assessment reports on the state family planning commission's first pilot counties/district on quality of care in family planning (1995-1998) (in Chinese). Beijing: China Population Press.

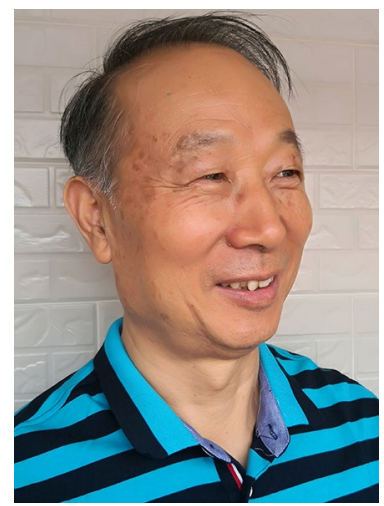

Zhenming Xie senior researcher and former deputy director of China Population and Development Research Center, and secretary general of the China Population Association (2008-2014); beginning in 1995 participated in the Quality of Care project, and served as head of the operational office of the Quality of Care project from 1999 to 2010. 